\title{
The Teaching Design of Flipped Classroom Based on New Constructivism*
}

\author{
Yahong Zhou \\ School of Foreign Studies \\ Anhui Sanlian University \\ Hefei, China 230601
}

\author{
Huan Chi \\ School of Foreign Studies \\ Hubei Normal University \\ Huangshi, China 435002
}

\begin{abstract}
The rapid development of Internet technology has a great impact on all walks of life. Flipped classroom and new constructivism theory emerge at the right moment. New constructivism emphasizes students' self-study, and puts forward that "meaning construction" is further sublimated on the basis of the application of knowledge to practice, which means realizing the innovation of knowledge. There are many commonalities between this theory and flipped classroom. The combination of the two can fully mobilize students' independent study, cultivate students' information literacy, promote the optimization of knowledge internalization, and improve students' knowledge innovation ability.
\end{abstract}

Keywords-new constructivism; flipped classroom; knowledge internalization

\section{INTRODUCTION}

In June 2016, the Ministry of Education issued the Thirteenth Five-Year Plan of Educational Informatization in order to fulfill the goal of Educational Informatization set in the Ten-Year Development Plan of Educational Informatization (2011-2020), which indicates that the Educational Informatization has been highly valued by the Ministry of Education and enters a new stage of rapid development. In July 2016, the China Internet Network Information Center released the 38th Statistics Report on the Development of the Internet in China, which shows that up to June 2016, the number of Internet users in China has reached 710 million, the Internet penetration rate has reached $51.7 \%$, and the number of mobile phone users has reached 656 million. The percentage of netizens at the age of 20-29 is the highest,up to $30.4 \%$, the proportion of students is still the highest of $25.1 \%$, and the percentage of college education is $20.4 \%$. The above data shows that the Internet has been integrated into the daily life of college students and becomes an essential part of their life. The rapid development of the Internet requires us to change the traditional teaching methods, eliminate the "two-skin" phenomenon of information and education, and strive to integrate information technology and teaching, and promote the modernization of education. The new constructivism theory and flipped classroom are the teaching theory and teaching method which emerge under the environment of rapid

*This paper is one of the research results of the school-level quality engineering project "Massive Online Open Course (MOOC) Business English Negotiation" (16zlgc020) development of information technology.

\section{NEW CONSTRUCTIVISM THEORY}

In 2011, Wang Zhuli put forward the new constructivism conception for the first time, of which the core theory is to cope with the challenges of the network times, especially the two difficult problems of information overload and knowledge fragmentation, and to realize the ultimate goal of learning - knowledge innovation. The concept knowledge of new constructivism holds that knowledge has three levels of structure, perceptual knowledge (primary structure), rational knowledge (secondary structure) and association (tertiary structure). Education is to "graft" the rational knowledge of predecessors to later generations, and make it the secondary structure knowledge of learners. The purpose of grafting is to realize the innovation of knowledge [1]. In the era of information explosion, the self-grafting ability of students is particularly important.

The traditional educational ideas think that learners should establish a "pyramid" knowledge structure, emphasizing the step-by-step tamping of the foundation before reaching the peak of success. In the age when the acquisition of knowledge is not convenient, this kind of learning method is appropriate. However, in the face of the information explosion of the network era, the traditional "pyramid" knowledge structure has been challenged, since the new constructivism learning theory puts forward the spiderweb knowledge structure. Spiderweb knowledge structure is a process in which learners actively construct knowledge based on their own interests, learning needs and problem solving. It encourages learners to search, research and learn knowledge according to their own needs on the network platform, so as to make their knowledge structure system expand round and round like a spiderweb. The ability to solve problems will be accordingly improved with the expansion of spiderweb. Because this spiderweb knowledge structure is built based on personal interests and needs, it is more targeted and practical.

The meaning construction mentioned in the traditional constructivism learning theory mainly refers to the understanding and application of the existing knowledge, while the construction in the new constructivism refers to not only letting knowledge stay at the stage practice, but also 
continuing to sublimate it and obtaining the innovation of the knowledge.

\section{THE SIMILARITIES AND DIFFERENCES BETWEEN THE NEW CONSTRUCTIVISM TEACHING METHOD AND FLIPPED ClassROOM}

Dr Dunbar's team uses a free-fall experiment to show whether "knowledge is reconstructed after learning the right scientific concepts" (see Dr Wei Yubo's blog for details). The experiment shows that the students in the physics department accept the correct scientific concepts, but when they found that the concepts are inconsistent with the previous concepts, the pre-concepts are activated, which shows that the correct scientific concepts are not reconstructed, but only be suppressed [2]. Zhao Xinglong points out that in the actual classroom teaching, the internalization of a concept, especially the internalization of the knowledge concepts which are complicated, non-wellstructured and cannot be spontaneously established, is far from enough only through one internalization. It can be mastered skillfully through many times of internalization and the application of scenarios [3]. The empirical study of this neuroscience is an important theoretical basis for flipped classroom. Different from the traditional classroom that is dominated by teachers' explanation, in the flip class, students study video resources and other learning materials in advance, which means that the students have carried on the first round of knowledge internalization before the class. The cooperation study and inquiry study in the classroom form the second round of internalization to the learned knowledge. The many times of internalization will be advantageous to the student to suppress the pre-concept better and provide the condition for the knowledge reconstruction.

There are many similarities between the new constructivism teaching method and flipped classroom. First of all, the new constructivism teaching method and the flipped classroom attach great importance to students' independent study. Flipped classroom is a model based on students' independent study and teachers are reasonably arranged as the facilitator to improve students' self-efficacy achieving the goal of cultivating students' self-study ability [4]. New constructivism has higher requirement on students' independent learning ability and requires students to acquire a great deal of information and knowledge in the network and life consciously according to their own interests and hobbies or under the guidance of teachers.

Secondly, the new constructivism teaching method and flipped classroom both pay attention to sharing and cooperation in the teaching process. In the flipped classroom, teachers design the corresponding teaching activities according to the students' pre-class feedback, and students discuss and communicate in the form of groups, which is not only beneficial to solve the difficult points, but also strengthen the internalization of the knowledge learned. Sharing is the first step of the new constructivism teaching method. Teachers let each student share the information and knowledge acquired in the classroom and form multiple interest groups according to their respective interests to carry out collaborative learning and inquiry learning.
There are also many differences between the new constructivism teaching method and flipped classroom. First, the content of flipped classroom is assigned by the teacher, while that of the new constructivism teaching method is decided by the students according to their interests or by the teachers and the students. The flipped classroom makes unified evaluation based on the subject goal while new constructivism teaching method makes individualized evaluation based on individual goal. The flipped classroom completes the teaching activities arranged by the teachers under the guidance of the teachers, while the new constructivism teaching method arrange the progress independently by each interest group, and carry out the cooperation or inquiry learning. The flipped classroom starts a new round of learning after the completion of the teacher's classroom learning activities, and the new constructivism teaching method continues to develop the network learning, and at the same time promotes the knowledge and ability by the ways of speaking, writing, and making, and so on to realize the integration of the fragments [5]. The new constructivism teaching method has higher requirements for the students' autonomous learning ability, learning motivation and the consciousness and ability of using the network to learn, so it is only suitable for the open and comprehensive course. Since it has higher requirements for the students' ability, it is difficult to be popularized in every subject. Therefore, the author tries to combine the new constructivism with the flipped classroom, which combines the essence of focusing knowledge innovation and internalization in the new constructivism teaching method and flipped classroom, so that the new teaching method can be applied in more classrooms.

\section{DESIGN AND IMPLEMENTATION OF FLIPPED Classroom TeACHING MODEL BASED ON NEW CONSTRUCTIVISM}

The basic meaning of flip classroom is to change the teaching process so as to advance the impartation of knowledge and promote the optimization of knowledge internalization. Ignoring the basic principle of knowledge internalization hidden behind the flipped classroom, the limitations of dislocation of relationship between teachers and students, the offside of knowledge difficulty, and the mistake in applicable object will occur in the teaching application, which makes the teaching only stay on the level of process flip. If it is only a superficial process flip, but refuses to pay attention to the basic principle of knowledge internalization in the process of flip, and the practical application of knowledge, the flipped classroom cannot really play its role. Most of the knowledge internalization ultimately achieves the goal of mastering knowledge through multiple internalization cycles [6]. Based on the new constructivism teaching method, the author tries to change the traditional flipped classroom from three steps to five steps, from the traditional "pre-class-in-class-after-class" to "pre-class - fist part of class - second part of class - third part of class-after-class". Different from the traditional flipped classroom of which the content is assigned by the teacher before the class, the theme of flipped classroom model put forward by the author is decided by the students 
and teachers together. The students should obtain information and knowledge before the class and share them in the class. This is not only a necessary part of the new constructivism teaching method, but also can train the students' ability of oral expression and information searching. In addition to the different pre-class part, there are differences in first part of class and after-class, see "Fig. 1".

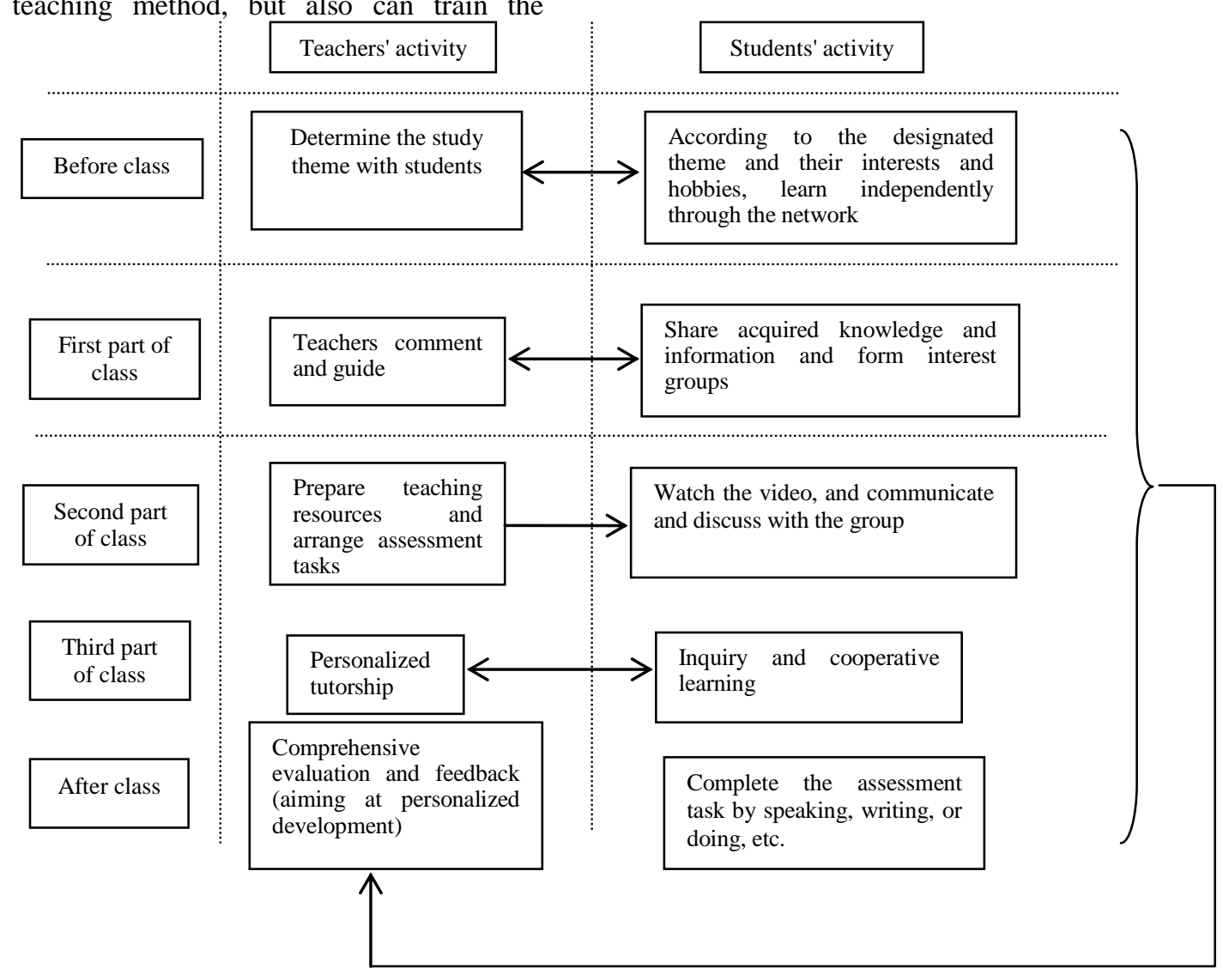

Fig. 1. Flipped classroom teaching model based on new constructivism.

The flipped classroom based on the new constructivism teaching method emphasizes the education idea of "studentcentered", and the teacher's main function is to guide. The model is mainly composed of two parts: student activities and teacher activities.

\section{A. Pre-class Stage}

New constructivism emphasizes that students should be taught to learn to choose, which means they need to break the traditional subject knowledge system, choose the content of study according to individual needs and interests, and construct personalized spider web knowledge structure. Therefore, unlike the traditional flipped classroom where the teacher directly assigns the learning content, the teaching model proposed by the author requires students and teachers to determine the learning theme together. For example, teachers provide students with a number of thematic options for choice or choose the content that students are interested in and are relatively consistent or close to the teaching goal from the themes proposed by students as the theme or content of next stage of learning and exploration.

\section{B. In-class Stage}

The course is divided into two stages, including first part of class and second part of class. In first part of class, students share the information and knowledge obtained on the Internet, and form interest groups according to their interests. The process of sharing information and knowledge includes the internalization, processing, transformation and output of information and knowledge. Generally speaking, these information and knowledge are related to the students' personal knowledge structure or the problems they face, which is likely to arouse the students' interest and attention, so the students are willing to make efforts to process the information and knowledge initially. The main responsibility of the teacher at this stage is to comment on the students' sharing and guide and organize the classroom. When students encounter difficulties and feel confused, teachers should share personal experience of online learning and organize students to continue online learning in the form of interest groups.

In the second part of class, students discuss and communicate with each other in the group according to the information and knowledge they have acquired, and discuss how to complete the assessment tasks assigned by the 
teachers together. When the students' activities are not carried out smoothly, teachers actively participate in to promote the activities to be carried out smoothly. For the questions with ready-made answers, teachers can take the teaching strategy. For the questions without ready-made answers, teachers should encourage and guide students to cooperate and explore.

\section{After Class Stage}

The after-class phase is also divided into two stages of third part of class and after class. Teachers make video or make use of open resources (such as open class of Harvard and Yale, Khan College courses, Chinese university courses, online classes and so on) for students to learn after class according to the theme determined with students in the third part of class. At the same time, they c should arrange assessment tasks to provide goals and directions for students' learning.

In the after-class stage, students continue to study online or in other forms individually or in groups. At the same time, students improve their knowledge and ability by speaking, writing and making to achieve debris integration. The teacher carries on the individuality appraisal mainly by the individual goal.

\section{THE Challenges of FliPPED ClasSRoOM} TEACHING MODEL BASED ON NEW CONSTRUCTIVISM

\section{A. Applicability of the Subject}

At present, the subjects of flipped classroom teaching experiments abroad are mostly science courses. The knowledge point of science is clear, since many teaching contents only need to clearly teach a concept, a formula, an example question, an experiment. Its discipline characteristic is convenient for implementation of flipped classroom, while the arts class curriculum involves the content of multiple subjects, which needs the teacher and the student to carry on the thought exchange, and the emotional communication to achieve the good teaching effect [7]. The flipped classroom based on the new constructivism proposed by the author is just the solution to this challenge. Before class, students obtain a large amount of information and knowledge according to their own interests and hobbies, which provides a knowledge reserve for future exchanges and discussions. The interest groups formed according to the students' interests also stimulate the students' learning enthusiasm. The presentation of the learning results by means of speaking and writing further promotes the internalization of knowledge. Moreover, all the teaching processes in the flipped classroom are centered on the students' interests, so the students are more willing to finish the learning tasks actively.

\section{B. Challenges to Teachers' Professional Competence}

In the flipped classroom, the teachers are no longer the absolute controllers of the class, nor the speakers, but the sharers, fuglemen and organizers [8]. Because the theme of the course is not appointed by the teacher, but decided by the student's interest, this has higher request to the teacher's professional ability. The teacher's understanding to this field must have the breadth as well as the depth ability to give the student the demonstration and the instruction in the study process; teachers should also have the ability of information literacy to not only record their own video, but also find appropriate resources from the open resources. Flipped classroom also puts forward certain requirements for teachers' classroom organization and management ability. Because students carry out learning in interest groups, teachers should guide these interest groups and timely step in to gradually promote the learning process when students encounter difficulties.

\section{The Ability of Students' Autonomous Learning and Information Literacy}

According to the new constructivism learning theory, human beings are faced with two challenges in the network age. One is information overload, which is how to process mass information into useful knowledge. The second is the fragmentation of knowledge, which refers to how to integrate the fragmented knowledge into a new personal knowledge system [9]. Before class, students need to obtain information and knowledge according to their own interests and hobbies In class, they should share the acquired knowledge, form interest groups, collaborate and explore learning, and report the learning results in the form of speaking and writing. All of these require students to have a strong ability of independent study and information search. Therefore, teachers should cultivate students' information literacy consciously in teaching.

\section{CONCLUSION}

The flipped classroom based on the new constructivism is a new teaching model in the network era. Under the impact of information overload and knowledge fragmentation, it aims at improving students' individual ability, paying attention to students' personalized development and advocating the cultivation of students' knowledge innovation ability. The teaching model has a higher requirement for students' autonomous learning ability and learning motivation. Teachers should fully evaluate students' ability when applying the model and carry out the flipped classroom in accordance with the learning situation. Because the whole process requires students to spend a lot of time collecting information and knowledge and reporting learning results, teachers can use this method in a certain course instead of the whole course. With the development and popularity of the network, the flipped classroom based on the new constructivism will certainly be promoted.

\section{REFERENCES}

[1] Wang Zhuli. Theoretical System and Innovative Practice of New Constructivism [J]. Journal of Distance Education, 2012.

[2] Resnick, L.. Education and Learning to Think [M]. Washington, D.C. National Academy Press, 1987. 
[3] Zhao Xinglong. The process of knowledge internalization and the design of teaching model in flipped classroom [J]. Modern Distance Education Research, 2014.

[4] Luo Chang. Analysis of College English flipped classroom in the Perspective of New Constructivism [J]. Journal of Minjiang University, 2016.

[5] Zhang Jinlei, Wang Ying, Zhang Baohui. Research on the flipped classroom Teaching Model [J]. Journal of Distance Education, 2012.

[6] Wang Zhuli. A preliminary study of new constructivism teaching method [J]. Modern Educational Technology, 2014.

[7] Wang Zhuli. New Constructivism: Learning Theory in the Network Age [J]. Journal of Distance Education, 2011. 